\title{
Social Capital and Community Preparation for Urban Flooding in China
}

\author{
Alex Y Lo \\ The Kadoorie Institute, University of Hong Kong, Hong Kong, China \\ Bixia Xu \\ Griffith School of Environment, Griffith University, Australia \\ Faith Chan \\ School of Geographical Sciences, University of Nottingham, Ningbo, China \\ Ruixian Su \\ School of Urban and Environmental Studies, Tianjin Normal University, China
}

Citation:

Lo, A.Y., Xu B., Chan F.K.S. and Su R. (2015) Social capital and community preparation for urban flooding in China. Applied Geography 64: 1-11.

DOI: http://dx.doi.org/10.1016/j.apgeog.2015.08.003 


\begin{abstract}
Social capital can enhance community resilience to environmental change. Productive and trusted relations among social actors and effectual social norms can help local residents share resources, information and risks. The main objective of our study is to understand the ways in which social attributes and risk considerations influence adoption of resilient economic measures by individuals for reducing potential losses due to catastrophic rainstorm and flooding. This article provides evidence from China on how social capital contributes to anticipatory adaptation to environmental change. The inquiry is based on structured interviews with local residents of Tianjin, a flood-prone port city in China, and a standard regression analysis. Findings show that the intention to make preparation increases with the levels of social expectation, social relationship, and institutional trust. Perceived risk and damage experience, however, have no significant impacts. This suggests that building social capacity and trust will be more effective in enhancing community resilience than merely increasing awareness of hazard risks. We call for greater efforts on strengthening the capacity of formal and informal communal institutions. The structural changes required, however, are challenging.
\end{abstract}

Keywords: social capital; community resilience; climate change adaptation; risk mitigation; flooding; China 


\section{Introduction}

Swathes of land are exposed to climate change disturbance as average temperatures are rising in the coming decades. The warming climate brings more energy into the meteorological system and results in a more vigorous hydrological cycle (Güneralp, et al., 2015). Some regions will receive more extreme precipitation and torrential rains. Coastal low-lying built-up areas are likely to experience rainstorm waterlogging and inundation more often than before. Older capital cities, in which human activities and settlements are concentrated and urban drainage systems have reached their capacity, are particularly vulnerable.

Middle-income countries, such as China, are economic victims of abrupt climate change. According to the World Bank (2010), natural hazards in the past 40 years accounted for a total of US\$2,300 billion in economic costs (in 2008 dollars). Middle-income countries incur the greatest proportional damage - more than poorer countries with few assets and richer countries which, with more capital, can more effectively prevent damage. Beijing, the capital of People’s Republic of China, recorded a total economic damage of over $¥ 10$ billion Chinese Yuan (approx. USD\$1.5 billion) and a large number of casualties (77 deaths and 1.6 million people affected) in a catastrophic rainstorm event in 2012 (Wu, 2012). Other megacities in China, such as Shanghai, Guangzhou, Tianjin, and Shenzhen, are also exposed to high risks of rainstorm waterlogging, flooding and/or hurricanes (Xie, et al., 2014). The changing climate threatens to increase the economic burdens on residents and communities by an order of magnitude.

Enhancing resilience to these impacts is a pressing issue. This can be achieved by encouraging residents to adjust household plans in ways that can reduce their potential economic losses from future extreme weather events, such as taking out flood insurance and diversifying income sources (Goulden, et al., 2013; Keil, et al., 2008; Lo, 2013). In developing countries, however, individuals and households encounter many barriers to adapting to climate change (Le Dang, et al., 2014; Suckall, et al., 2014). One of these barriers is the lack of, or misperception of, information on hydrological risks. It is often assumed that the intention to make preventive arrangements for flooding is a function of perceived risk (Kunreuther, 1996, 2006). Misperception and myopic attitudes would result in delays or failures in undertaking 
preventive actions ahead of time to reduce the potential impacts of natural hazards on households and communities. In reality, many ordinary people tend to see the likelihood or severity of a natural hazard event causing damage to their property and affecting their livelihood as being sufficiently low. Systematic misperception of flood risks is identified as the main reason for poor or inadequate preparation for catastrophic flooding events (Kunreuther, 1996, 2006; Miceli, et al., 2008).

However, recent research has suggested that the importance of risk perception has been overstated. Based on a German case study, Bubeck et al. (2013, p. 1336) conclude that "risk perceptions rarely relate significantly to improved flood mitigation behaviour". An Australian survey reported by Lo (2013) has come to the same conclusion. More evidence can be found in Bubeck et al.'s (2012) meta-analysis of 16 relevant empirical studies. Rather than taking risk perception (and hazard experience) for granted, researchers have increasingly turned their focus toward social capital, which refers to the structure of relations among social actors (Coleman, 1990; Pretty \& Ward, 2001). Social capital can help enhance the capacity of households and communities to cope with climate change impacts (Bihari \& Ryan, 2012; Goulden, et al., 2013), although in some cases it contributes to vulnerability (Wolf et al., 2010). Variations in the level and form of social capital could explain people's willingness to make hazard adjustments. The quality of social norms and interaction with people around and the community has significant implications for anticipatory adaptation to climate change (Eriksen \& Selboe, 2012; Frank, et al., 2011).

This research is situated in the context of a developing country in search of more effective ways for enhancing community resilience to extreme weather events and reducing burdens on local communities. We focus on voluntary economic preparation the household level, which is an area of research that requires more attention than it has received, given its practical implications for state economic planners and aid organizations (Alinovi, et al., 2009; World Bank, 2010). Local research efforts remain inadequate in China, which is home to a great number of flood-prone and densely populated cities and towns. Existing Chinese studies have centred on the effects of human cognition and hazard experience in driving behavioral 
response (Ge, et al., 2011; Huang, et al., 2010; Lo \& Cheung, 2015; Yu, et al., 2013; Zheng \& Dallimer, 2015). Few attempts have been made to utilize the concept of social capital. We bring the idea of economic resilience (Alinovi, et al., 2009; Rose, 2004, 2007) together with investigations of the role of social capital in fostering behavioral adjustments to environmental change. Findings will be useful for identifying critical factors influencing the intention to act and formulating strategies for promoting risk management and preparation for extreme weather events at the household level.

This paper reports a quantitative study aimed at examining how social attributes and risk considerations influence voluntary adoption of resilient economic measures by individuals. Evidence was solicited from structured interviews with local residents of Tianjin, China. In the next section, we further elaborate on the conditions and utility of social capital. Then, we introduce the study area and survey instrument, followed by a statistical analysis of survey data. In the last section, we summarize findings and reflect on the issues being addressed.

\section{Social capital and adaptation to environmental change}

Social capital captures the idea that social relations and social norms form the basis of sustainable communities. It is generated and accumulated in the processes of social interaction and engagement with social networks and institutions, both formal and informal ones, yielding a wide range of economic and societal benefits. While Coleman (1990) understands social capital as a largely unintentional outcome of social interactions and organization, Putnam (1995, p. 664-665) defines it as an enabler of collective action: "features of social life - networks, norms and trust - that enable participants to act together more effectively to pursue shared objectives". Pelling and High (2005) describe Putnam's (1995) definition as the most frequently used and widely accepted one, which is therefore adopted for the present paper.

Social scientists have found the concept with multiple, analytically distinctive dimensions. Pelling and High (2005, p. 310), for example, note that social capital consists of two complementary components, namely, interpersonal relationship, and trust and reciprocity. 
Interpersonal relationships are developed from social ties, networks, and connections. Extensive and close interpersonal relationships are an outcome of trust and reciprocity, which reduce transaction costs and encourage cooperative behavior. Conformity to common expectations may also nurture social capital. As Pretty and Ward (2001, p. 211) suggest, the four critical aspects of social capital are 1) relations of trust; 2) reciprocity and exchanges; 3 ) common rules, norms and sanctions, and; connectedness, networks and groups. Adger (2003, p. 389) describes the concept in similar terms, encompassing relations of trust, reciprocity and exchange, evolution of common rules, and networks. The first, second and fourth dimensions outlined by Pretty and Ward (2001) and Adger (2003) match the two conceptual components identified by Pelling and High (2005), while the third dimension has nuanced connotations. Common rules, norms and sanctions render other people's action predictable, reduce uncertainties in the outcomes of a particular action, and give individuals the confidence to invest in related activities. These manifestations of social capital are conducive to motivating collective action that would otherwise be deemed to be too costly to undertake.

Social capital among members of a community is a key determinant of its vulnerability and resilience to environmental changes and uncertainties (Adger, 2000, 2003; Barnett \& Eakin, forthcoming; Frank, et al., 2011; Goulden, et al., 2013; Pelling, 2011; Wilson, 2015). Adger (2003, p. 401) has argued that "many aspects of adaptive capacity reside in the networks and social capital of the groups that are likely to be affected". The structure and quality of social relations select what impending changes to act upon and determine the type and range of options for coping with these changes. Frank et al. (2011) find that the ways in which Mexican farmers understand and respond to climate-related threats to their welling and livelihoods are shaped by their perception of themselves in relation to others in the community, whereas risk perception and experience alone do not have significant influence on the motivation to adopt adaptive measures. Similarly, Goulden et al. (2013) report that the social connections among Ugandan villagers contribute to household resilience by facilitating livelihood diversification through providing access to resources and livelihood opportunities, access to credit, reducing costs of engaging in activities, facilitating migration, etc. Social capital links give households more opportunities for mitigating and spreading the risks of environmental change. 
Yet, the accumulation of social capital is not necessarily a social 'good' and may create perverse incentives undermining adaptive capacity (Pelling and High, 2005; Pelling, 2011). Established networks, norms and trust, in Putnam's (1995) terms, may perpetuate social relations and practices that are counter-productive or detrimental to adaptation to condition changes. For example, in Norway, the cultural and social norms of appreciating local history and recalling the collective memory about the home town in which local residents live had contributed to the social organization of denial of climate change, which has a salient orientation towards long-term futures and requires forward-thinking (Norgaard, 2011). High levels of trust in the state, especially post-communist regimes that used to assume full responsibilities for central planning (Vari, et al., 2003), may result in an expectation among potential victims that generous post-disaster reliefs and home reconstruction assistance would be provided if natural perils occur, and consequently, lead to delays in undertaking preventive actions, a common problem known as 'moral hazard'. Wolf et al.'s (2010) British case study shows that the social networks of elderly people could perpetuate narratives of independence, capability and resilience and consequently contribute to their vulnerability to heat waves rather ameliorating it. Thus, the structure of social relations and practices has mixed impacts on subjective experience with condition changes and voluntary adoption of adaptive measures. The relationship between social capital and adaptation to climate change is complex and not invariably a positive one (Pelling, 2011; Wolf, et al., 2010).

Therefore, the notion that social capital is instrumental to fostering proper behavioral adjustments to the prospects for extreme weather events cannot be taken as given. This issue requires further investigation in the context of China, where the state continues to dominate urban management and assume the primary responsibility for managing flood risks, with the possible consequence of displacing the motivation of the general public to manage these risks. Our study sought to ascertain how social capital attributes influence voluntary adoption of resilient economic measures in a Chinese urban community. To examine the claim that adoption of such measures is poorly informed by risk perception and hazard experience (Bubeck, et al., 2012; Bubeck, et al., 2013; Frank, et al., 2011; Lo, 2013), we also included these elements in the analysis. The inquiry was guided by two working hypotheses: Intended 
economic preparation for catastrophic rainstorm waterlogging and flooding is significantly related to 1) risk perception and hazard experience and 2) attributes of social capital. A case study of Tianjin is introduced below.

\section{Urban flood hazards in Tianjin}

Tianjin is located in the northeastern part of North China Plain area and adjacent to Beijing and Hebei Province (Figure 1). The city is the fourth largest in China by urban population and the third largest by urban area, consisting of six urban districts, along with four suburban districts and five counties. Tianjin has experienced phenomenal socio-economic growth since China embarked on the far-reaching economic reforms in the late 1970s, and continues to be a major industrial powerhouse in the country. In 2013, the city recorded a high GDP growth rate at 12.5 per cent (Tianjin Bureau of Statistics, 2014) and GDP per capita $¥ 97,622$ Chinese Yuan (approx. USD $\$ 14,360$ ) (National Bureau of Statistics of China, 2014). A large number of job-seeking migrants from rural China have moved to Tianjin, driving housing needs and urban sprawl (Chan, et al., 2012). Municipal population has risen from 9.3 million in 1993 to over 14.7 million in 2013 (Tianjin Bureau of Statistics, 2014). Although urban development can enhance people's well-beings by driving infrastructural development (e.g. mass transit), it may reinforce some environmental threats, such as increasing the risks of rainstorm waterlogging and flooding.

The city of Tianjin is situated at the outlet of a major tributary, namely Yongding River in Haihe River basin. Fluvial discharge passes through the city to Bohai all the way from Beijing and the Northern China, putting it under threat of fluvial (riverine) flooding. The urban drainage system is likely to reach its capacity on the release of peak flow during the storm period, because rapid urbanization has increased the area of concrete surface and diminished penetration or infiltration of the surface runoff into soil (Han, et al., 2006). Moreover, massive

urbanization and new coastal settlements have contributed to dramatic land-use changes in Tianjin. Grey infrastructure has replaced vast areas of blue-green sites that naturally restore stormwater, such as forest and grassland, and regulate coastal tides and surges, such as wetlands. The loss of wetland, in particular, accelerates land subsidence in the city (Yi et al., 
2014). Land subsidence causes gradual shrinking of ground-surface elevation, consequently increasing the risk of coastal flooding and sea water intrusion during dry season (Wang, 1998). These hazards are aggravated by the rising sea levels along the Bohai and Yellow River areas by approximately $2.2 \mathrm{~mm}$ per year (Varis, et al., 2012). These factors combined, including increasing population and economic activities, land-use changes, accelerating sea level rises and surges, have increased the risks of flooding confronted by Tianjin (Fuchs, et al., 2011; Wang, et al., 2014).

On $21^{\text {st }}$ July 2012, the heaviest rainstorm in six decades hit Beijing and caused the tragic death of 77 residents ( $\mathrm{Wu}, 2012$ ). Cloudbursts and floodwaters also passed through Tianjin, which is $114 \mathrm{~km}$ to the southeast of Beijing. The Tianjin city was ravaged by torrential rain by days and experienced two hits of heavy rainfalls. During the first heavy rain event from 23:30 on the $21^{\text {st }}$ July 2012 until 6:00 of the next day, Tianjin city centre recorded an average rainfall of $74 \mathrm{~mm}$. Rainfall in Hebei and Hongqiao, two of the six urban districts of Tianjin, exceeded official 'Heavy Rainstorm' Levels. Acute and prolonged intensive rainfall resulted in severe waterlogging in 18 places of the city centre, causing significant damage on properties and infrastructure (Tianjin Water Authority, 2012).

Tianjin suffered from a second heavy rainstorm hit in the $25^{\text {th }}$ and $26^{\text {th }}$ of July 2012 . The central and southern areas received 'Rainstorm' to 'Heavy Rainstorm' levels. There were 28 automatic rainfall monitoring stations in Tianjin. Twenty six of these stations reported accumulated rainfall of over $100 \mathrm{~mm}, 17$ stations reported rainfall of over $150 \mathrm{~mm}$ with the peak value of $176.8 \mathrm{~mm}$ found at Tuanjiebeili Station during the 17-hour storm that started on $25^{\text {th }}$ July at 7:00 and lasted until mid-day of the next day. An area of nearly $160 \mathrm{~km}^{2}$ suffered waterlogging and 69 places exceeded $300 \mathrm{~mm}$ of rainfall (Li, 2014, p.32-33). With an average of almost $147.6 \mathrm{~mm}$ of rain falling in the city of 14.7 million people, the deluge breaks records for rainfall in Tianjin since the historical flooding in 1963 and 1996 (Tianjin Water Authority, 2008). Part of the Jixian County, a suburb in northern Tianjin, was inundated, and 1106 residents and 260 tourists were forced to evacuate (Li, 2014, p.33). The heavy rainstorm disrupted telecommunication in Jixian area and wreaked havoc at the Tianjin Binhai International Airport. 
More than 54 inbound and outbound flights were rescheduled or cancelled (Li, 2014, p. 33). The '1-in-100-year' rainstorms and urban inundation raise concern about the capacity of Tianjin's drainage networks for handling massive deluge. These catastrophic events have stirred up public criticisms against city managers and the quality of urban infrastructure amid rapid urbanisation.

Climate change complicates flood risk management in Tianjin as these urban flood hazards are likely to become more frequent and intense in the coming years. Local communities and households are exposed to escalating risks of property damage and rising economic losses, due to the rapid socio-economic development in the larger Beijing-Tianjin-Hebei region and increases in the values of economic activities and assets. It is imperative to promote voluntary adoption of resilient economic measures to reduce the damage and recovery costs borne by city management and the households themselves. Our study was designed to shed light on this endeavor.

\section{Research methods}

Survey questions

The study involved a structured questionnaire survey of Tianjin residents. The questionnaire collected four sets of information. The first one was the respondents' motivation to make preventive arrangements for coping with disruptive urban flood hazards in the Tianjin city. Respondents were asked to express their intention to adopt strategies that could reduce potential economic losses due to catastrophic rainstorms and flooding. Five close-ended questions were included, each presenting an attribute of economic resilience, namely, consumption elasticity (reducing expenditures), access to insurance (recovering damage), asset mobility (reducing losses), income diversity (maintaining economic functioning), and asset distribution (reducing losses). All of these questions were read in the context of urban flood hazards and preceded by a brief discussion with the interviewer on the past and future rainstorm or flooding events in Tianjin. The design of the question statements was informed by 
key research reports, notably Alinovi et al. (2009) and World Bank (2010). Responses were measured on a five-point Likert scale. Higher scores denote stronger intention to adopt resilient economic strategies as a means to reduce potential losses in the event of catastrophic rainstorms and flooding.

Another set of survey items recorded respondents' experience with rainstorm and flooding events and their perception of these risks. A binary (yes/no) item ascertained whether the respondents had incurred any damage from a rainstorm or flooding event, followed by a five-option qualitative question inquiring the extent of damage. The ensuing questions were used to measure perceived likelihood and severity of severe urban inundation in the future: how likely is Tianjin to experience a major catastrophic event like the 2012 rainstorms? and how much personal damage would it cause? Respondents were then requested to consider how likely such hazard events would become more frequent and intense in the next two decades. All items, except the first one, were measured on a five-point scale.

Social capital variables were constructed broadly following Putnam's (1995) definition, encompassing aspects of networks, norms and trust in social life. Eight specific survey items gauged the strength of social-normative effects on respondents (e.g. "do you think your family would encourage you to prepare for urban flood hazards?"), the quality of social relationships (e.g. "how is your relationship with your friends?"), and the level of trust in institutions (e.g. "do you trust that your local residential committee can help residents cope with the impacts of urban flood hazards?"). Responses were recorded on a five-point scale. Exact wording and response options can be found in Appendix. Since these questions solicited evidence on social capital from a subjective point of view (i.e. the respondents' self-assessment), care is required when comparing with other studies that use objective, behavioral indicators, such as membership in social organizations.

Personal characteristics were included in the statistical analysis as control variables. Four questions recorded respondents' age, education, sex, and monthly income. An additional one asked whether their current home is located at the ground floor of a residential building (the great majority of residents in Tianjin's core city area live in densely packed multi-storey 
buildings). This is an important control measure because ground-floor units and assets are vulnerable to inundation and their occupants may be predisposed to risk mitigation.

\section{Data collection}

The study sites are located at the six central administrative districts of the Tianjin city, namely, Heping, Hedong, Hexi, Nankai, Hebei, and Hongqiang, which are exposed to threat of flooding and have a very high concentration of people, infrastructure and economic activities. Figures 2 and 3 show a selected view of the study sites, focusing on the urban form and the ground setting respectively.

\section{[FIGURES 2 and 3 ABOUT HERE]}

Face-to-face interviews were conducted in the public areas. Sample was distributed amongst these districts approximately in proportion to local population size. Two or three major public parks or neighbourhood parks were identified from each of the selected districts as study sites. The selection was based on proximity to housing clusters, pedestrian traffic, and feasibility for conducting intercept survey. Park visitors were invited to complete the questionnaire, which lasted about $8-10$ minutes each. A certain number of passers-by were also inadvertently included, since urban parks in Tianjin's core city area are tightly integrated with the street footpath system with high pedestrian traffic. It is difficult to distinguish between bona fide park 'visitors' and 'non-visitors'. Thus the sample included both park visitors and pedestrians passing-by the parks.

One out of every three park visitors or passers-by over 16 years old was selected as respondents. Only residents of the six core districts were invited to participate. Two screening questions presented at the outset help achieve the age and residence requirements. We employed sampling quotas, which were determined by age and gender distribution in the district concerned (according to the latest available census data), as these personal characteristics are normally observable from appearance. Trained interviewers approached a particular age group and/or gender group when the sampling quota for the remaining age or 
gender groups had been exhausted. Despite our every effort to obtain a broadly representative sample, we did not seek to generalize our findings across the entire population and the primary objective was to examine the relationship between behavioral intention and normative factors.

A local university provided logistic support to the survey and assisted in interviewer recruitment. Five undergraduate students with prior interview experience were recruited as interviewers and coached in the procedures of the survey. A Mandarin-speaking faculty member supervised the fieldwork. Those individuals who completed the questionnaire received a token as incentive. Survey activities took place between July and October 2014.

\section{Results}

The research team invited 593 Tianjin residents to take part in the survey in the designated public areas. Response rate was 63\%: 375 individuals accepted the request, while 218 refused. There were 43 withdrawals or incomplete questionnaires, which were subsequently excluded from analysis. The final sample consists of 332 observations. We processed the data using a standard statistical package (i.e. STATA) and performed an OLS regression analysis. The main purpose was to use social capital and risk perception variables to predict intended economic preparation for urban flood hazards. Further details on the distribution of responses are available in the Appendix.

\section{Sample characteristics}

Respondents' ages range from 16 to 90, and the average value lies between 40 and 41 . Fortynine per cent of them are females, and forty-two per cent hold a university or higher degree. One-third of respondents (34.5\%) have a monthly household income of $¥ 5,500-¥ 9,000$ Chinese yuan (approx. US\$891 - US\$1,460), and $21.4 \%$ have $¥ 9,000$ or above. Less than $15 \%$ earn $¥ 3500$ (approx. US\$567) or less per month. There were 20 missing values in monthly 
income due to non-response. Ground-floor residents exposed to the risk of inundation represented 13 per cent of the sample.

\section{Intended economic preparation}

Table 1 presents the mean values, standard deviations and factor loadings of the intended preparation variable. Respondents indicated varying degrees of economic preparedness for urban flood hazards. As a widely used tool for risk mitigation, insurance received the greatest support. Most of the respondents (71.4 per cent) ${ }^{1}$ intended to sign up to relevant insurance schemes to cover their potential losses arising from urban flood hazards. More than half (58.6 per cent) would adjust their daily spending patterns if costs of living vary from normal levels due to extreme weather. Only one-third (33.7 per cent) would make contingency arrangements against such events for temporarily moving their valuable assets to a safer place. Fifty-three per cent were prepared to identify multiple sources of income. Nearly half (48.5 per cent) had considered acquiring properties or motor vehicles in other districts in order to spread the risks of natural hazards. The five survey items measuring respondents' economic preparedness were factor analyzed, using the Principal Component Analysis with Varimax rotation. Results show that these five variables loaded on one factor (Table 1), suggesting that they reflect one single latent variable and represent a particular disposition. Also, these variables collectively achieved an acceptable Cronbach's alpha value (0.65), meaning that the composite scale Intended economic preparation, created by adding up the five items, is statistically reliable. Higher values in Intended economic preparation denote greater intention to prepare for hazards

Hazard experience and risk perception

A small number of the Tianjin residents interviewed (16 per cent) had recorded some economic losses during a rainstorm or flooding event in the city. When asked how damaging the last one

\footnotetext{
${ }^{1}$ Figures presented in this paragraph denote the proportion of respondents selecting the options of 'Probably' or 'Definitely' in responding to relevant question. See Appendix for details.
} 
was to them and their family, 12.5 per cent of the respondents indicated some damage and about 2 per cent described it as very damaging. Nevertheless, a lot more people anticipated a certain level of damage if heavy rainfall and waterlogging at the same magnitude as in 2012 returned to Tianjin. Twenty seven per cent of respondents expected some damage, whereas 11 per cent indicated that impacts on their wellbeing would be significant. On perceived likelihood of hazards, the majority believed that the 2012 event is likely to return in the next 10 years, i.e. 42.9 per cent selected the 'maybe' option and 21.6 per cent indicated 'possible' or 'very likely'. When asked how likely such hazards would intensify and occur more frequently in the longer term (20 years), 44 per cent responded 'maybe' and 15.9 per cent 'possible' or 'very likely'.

\section{Social capital}

Most of the individuals expressed some social-normative considerations (Table 2). More than half believed that they were expected - by their family (65.6 per cent) and friends (66.2 per cent) - to prepare for urban flood hazards. Fewer suggested that such expectation would come from neighbors or other people in their local residential community (48.9 per cent). As usually expected, the strength of social ties varies by the type of relationship. More than 90 per cent had 'good' or 'very good' relationship with their family. The number went down slightly to about 87 per cent when friends were concerned. Much fewer (55.4 per cent) made the same evaluations for their neighborhood relationship. The two items on trust revealed a modest level of division among respondents. While half of them (55.2 per cent) trusted city planners and administers, nearly one-fifth (19.2 per cent) expressed skepticism. Local residential committees $(j u ̄ \text { wěi hui })^{2}$ were seen as less capable of dealing with natural hazards. Some of the residents we interviewed suggested that these committees lack substantive power and material resources essential for organizing effective response to major changes and catastrophes. Overall, about one-third (31.6 per cent) trusted their residential committee, but more people

\footnotetext{
2 In Mainland China, jū wěi huì, which literally means 'residential committees', are the most basic form of official community organization. They can be found in every local administrative area in urban China and are managed by government agencies. Their responsibilities include providing residential services, maintaining social order, managing residential environment, and engaging local community in official activities.
} 
(35.9 per cent) held the opposite view. As shown in Table 2, the social capital variables were split up into three factors corresponding to their conceptual categories, which can be called 'social expectation', 'social relationship' and 'Institutional Trust'. They managed to achieve acceptable alpha values and were added up to form three composite variables accordingly. In general, higher values denote more social capital.

\section{Relationships between variables}

The regression analysis included all of the survey items described above. Intended economic preparation was used as the dependent variable and regressed on respondents' socio-economic characteristics, hazard experience and perception, and social capital items. Descriptive statistics are displayed in Table 3.

Table 4 displays the OLS regression model. The model yielded an adjusted $R^{2}$ of 0.39 , suggesting that the independent variables listed in the table explained 39 per cent variations in Intended economic preparation. Multi-collinearity was not detected as none of the explanatory variables yielded a Variance Inflation Factor (VIF) value greater than 5. By usual standards, an explanatory variable with a p value lower than 0.05 is considered to be statistically significant.

Only two of the socio-economic variables have significant impacts on the intention to act, namely, age and income, which demonstrated negative and positive effects respectively. Younger and higher-income people had stronger motivation than others to adopt adaptive measures for coping with severe urban flood hazards. It is noteworthy that living in a groundfloor unit, which is a proxy for physical vulnerability, was not a key factor. Intriguingly, none of the risk-related variables achieved statistical significance at the 5 per cent level, suggesting that flood victims and risk-aware individuals were not more likely to make advance arrangements for future hazards. On the other hand, all of the three social capital variables indicated moderately strong and positive effects on intention. Those individuals who were subject to greater social expectations, had better relationships with other social actors, and tend to trust relevant institutions were more likely to adopt resilient economic measures. 


\section{Discussion and conclusions}

Social capital is crucial for enhancing community and household preparedness for shocks and abrupt environmental changes. Productive and trusted relations among social and organizational actors and the effectual social norms engendered are a vital source of economic resilience to environmental change. But social capital is not a universal common good and may create perverse incentives and a false sense of security, leading to delayed action or maladaptation (Pelling, 2011; Wolf et al., 2010). Inquiry into its complex implications for hazard adjustment and adaptation remains an incomplete project.

The pivotal role of social capital warrants greater efforts by Chinese researchers. Existing local studies tend to put more emphasis on human cognition and hazard experience than social-normative and relational dimensions. For instance, Huang et al. (2010), Ge et al. (2011) and Yu et al. (2013) conclude that what the Chinese government needs to do is to provide more hazard information to the general public and improve knowledge-based communication of risk. Zheng and Dallimer (2015) have made similar recommendations, although they go further by bringing up personal-subjective factors. Many Chinese studies on public response follow the 'information-deficit' model (Lo, et al., 2012; Owens, 2000). The idea that low perception and awareness of risk is the main barrier to enhancing community preparedness for disruptive environmental change is well received.

Our study contributes to these debates by investigating the systematic relationship between social capital and household economic resilience in the context of a flood-prone port city in China. It demonstrated the statistical effects of social capital and risk perception on the intention of Tianjin residents to adopt resilient economic measures for coping with urban flood hazards. We found no observable evidence supporting the standard assumption that perceived risk and damage experience positively contribute to hazard adjustments. Consistent with these results, we noted that ground-floor residents, who are particularly vulnerable to waterlogging and inundation, did not indicate stronger motivation to act than others. Our first research hypothesis is therefore not supported. Nonetheless these findings corroborate those of Bubeck 
et al. $(2012,2013)$ and Lo (2013), and imply that merely providing more hazard information and improving public understanding of risk are insufficient. Alternative strategies are needed to make management interventions effective.

Utilizing social capital is a promising way for engaging households in hazard risk mitigation and climate change adaptation (Frank et al., 2011; Bihari and Ryan, 2012; Lo, 2013). Wang, et al. (2012) have suggested that risk managers in China should give higher priority to strengthening residents' social networks and their engagement with local community as a means to improve community preparedness for natural hazards. Our study provides empirical support to this recommendation by demonstrating that social capital has significant positive impacts on economic preparation for catastrophic rainstorm and flooding. Residents' intention to make advance arrangements for reducing potential economic losses due to such hazards increased with the levels of social expectation, social relationship, and organization trust. The more social capital one has accumulated, the stronger motivation to act. This offers evidence for our second hypothesis and indicates the importance of building closer ties and trusted relations among social and institutional actors for enhancing household and community resilience. Strengthening these aspects of people's social life will be conducive to reducing their economic losses and ultimately the costs borne by government agencies in the prospects of more intense and frequent natural hazards in the coming decades.

The findings echo the calls by international researchers for addressing the link between climate change adaptation and prevailing social structures and institutions. Social networks and trusted relations facilitate the exchange of information and resources, and provide greater access to opportunities that can help absorb economic shocks and reduce risks. These networks and associated flows of information and resources between individuals and groups oil the wheels of decision making (Adger, 2000, 2003). It is imperative to build capacity for social collectives and local community groups to respond to climate change (Pelling and High, 2005; Pelling, 2011). Based on the results of the Tianjin survey, we suggest that the accumulation of social capital through trusted networks and institutions can help enhance Chinese residents' preparedness for the consequences of accelerating climate change. This requires greater efforts 
on strengthening the adaptation functions of formal and informal communal institutions, such as residential committees and mutual-aid cooperatives, respectively. Although these social considerations and measures have proven elsewhere to be important for enhancing resilience, the unique context of China has created a multitude of hurdles.

Our recommendation points to a governance issue that requires structural reforms. An enduring problem in the present-day China is that social cohesion among urban residents has declined over the past few decades, as a consequence of increasing internal migration, income disparities, and uneven development. Our interviews with local residents reveal that they had little trust in people outside their immediate social circles, and this appears to be a matter of social ethos rather than isolated individual dispositions. Moreover, the Chinese government continues to impose many restrictions on non-state social organizations, posing constraints on the organic growth of the civil society. Consequently, the number and capacity of informal social institutions within cities are limited. As a frontline government agency, residential committees could play a more active and important role in hazard risk management, but they lack authority and resources to assume more responsibilities and augment their capacity in social organization. The conventional top-down approach of social governance in China constitutes a hurdle for strengthening the social function of local organizations that are more capable of fostering social connections and enhancing household adaptation.

Apart from moving beyond the information-deficit model, decision-makers in China should allow greater empowerment in social participation and build adaptive capacity at the 'grassroots' level. Our findings therefore lend support to the bottom-up approaches of governing flood risks. Community-based social innovations, such as encouraging public-public partnerships (e.g. between non-governmental cooperatives and government agencies) and engaging long-term residents in volunteer stewardship programs (Bihari and Ryan, 2012; Suckall et al., 2014), are much welcomed.

On methodology, we suggest that further research based on social surveys should include objective, behavioral indicators of social capital, such as the individuals' membership in social organizations and trade unions, the number of neighbors they know, the frequencies of 
participating in church activities and political elections, etc. Individual household surveys can hardly capture the notion of social capital in its entirety, which is a property of the society at large and embedded into social structures and institutions. Survey designers need to recognize the multiple dimensions of the concept and the various sites for socialization in which it accumulates. Although extensive surveys have their limits in fully capturing the concept, behavioral indicators could at least mitigate the inherent ambiguities and inconsistencies in self-assessing the quality of social relationship and the level of trust. The use of alternative measures would be useful for cross-checking the results and could strengthen the argument for addressing social dimensions.

\section{Acknowledgements}

This research was funded by the Academy of the Social Sciences in Australia under the Australia-China Joint-action Program and the Griffith Climate Change Response Program at Griffith University. The authors appreciate the research assistance provided by students at the Tianjin Normal University. 


\section{References}

Adger, W. N. (2000). Institutional Adaptation to Environmental Risk under the Transition in Vietnam. Annals of the Association of American Geographers, 90 (4), 738-758.

Adger, W. N. (2003). Social Capital, Collective Action, and Adaptation to Climate Change. Economic Geography, 79 (4), 387-404.

Alinovi, L., Mane, E., \& Romano, D. (2009). Measuring household resilience to food insecurity: application to Palestinian households. In EC-FAO Food Security Programme: Linking Information and Decision Making to Improve Food.

Barnett, A. J., \& Eakin, H. C. (forthcoming). "We and us, not I and me": Justice, social capital, and household vulnerability in a Nova Scotia fishery. Applied Geography.

Bihari, M., \& Ryan, R. (2012). Influence of social capital on community preparedness for wildfires. Landscape and Urban Planning, 106 (3), 253-261.

Bubeck, P., Botzen, W. J. W., \& Aerts, J. C. J. H. (2012). A Review of Risk Perceptions and Other Factors that Influence Flood Mitigation Behavior. Risk Analysis, 32 (9), 1481-1495.

Bubeck, P., Botzen, W. J. W., Kreibich, H., \& Aerts, J. C. J. H. (2013). Detailed insights into the influence of flood-coping appraisals on mitigation behaviour. Global Environmental Change, 23 (5), 13271338.

Chan, F., Mitchell, G., \& McDonald, A. T. (2012). Flood risk appraisal and management in mega-cities: a case study of practice in the Pearl River Delta, China. Water Practice \& Technology, 7 (4).

Coleman, J. (1990). Foundations of social theory. Harvard University Press, Boston, MA.

Eriksen, S., \& Selboe, E. (2012). The social organisation of adaptation to climate variability and global change: The case of a mountain farming community in Norway. Applied Geography, 33 (0), 159167.

Frank, E., Eakin, H., \& López-Carr, D. (2011). Social identity, perception and motivation in adaptation to climate risk in the coffee sector of Chiapas, Mexico. Global Environmental Change, 21 (1), 66-76.

Fuchs, R., Conran, M., \& Louis, E. (2011). Climate Change and Asia's Coastal Urban Cities. Environment and Urbanization Asia, 2 (1), 13-28.

Ge, Y., Xu, W., Gu, Z.-H., Zhang, Y.-C., \& Chen, L. (2011). Risk perception and hazard mitigation in the Yangtze River Delta region, China. Natural Hazards, 56 (3), 633-648.

Goulden, M. C., Adger, W. N., Allison, E. H., \& Conway, D. (2013). Limits to Resilience from Livelihood Diversification and Social Capital in Lake Social-Ecological Systems. Annals of the Association of American Geographers, 103 (4), 906-924.

Güneralp, B., Güneralp, İ., \& Liu, Y. (2015). Changing global patterns of urban exposure to flood and drought hazards. Global Environmental Change, 31 (0), 217-225.

Han, S.-q., Xie, Y.-y., Li, D.-m., Li, P.-y., \& Sun, M.-I. (2006). Risk analysis and management of urban rainstorm water logging in Tianjin*. Journal of Hydrodynamics, Ser. B, 18 (5), 552-558.

Huang, L., Duan, B., Bi, J., Yuan, Z., \& Ban, J. (2010). Analysis of Determining Factors of the Public's Risk Acceptance Level in China. Human and Ecological Risk Assessment: An International Journal, 16 (2), 365-379.

Keil, A., Zeller, M., Wida, A., Sanim, B., \& Birner, R. (2008). What determines farmers' resilience towards ENSO-related drought? An empirical assessment in Central Sulawesi, Indonesia. Climatic Change, 86 (3-4), 291-307.

Kunreuther, H. (1996). Mitigating disaster losses through insurance. Journal of Risk and Uncertainty, 12 (2), 171-187.

Kunreuther, H. (2006). Disaster Mitigation and Insurance: Learning from Katrina. Annals of the American Academy of Political and Social Science, 604, 208-227. 
Le Dang, H., Li, E., Nuberg, I., \& Bruwer, J. (2014). Farmers' assessments of private adaptive measures to climate change and influential factors: a study in the Mekong Delta, Vietnam. Natural Hazards, 71 (1), 385-401.

Lo, A., \& Cheung, L. O. (2015). Seismic risk perception in the aftermath of Wenchuan earthquakes in southwestern China. Natural Hazards, 78 (3), 1979-1996.

Lo, A. Y. (2013). The Role of Social Norms in Climate Adaptation: Mediating Risk Perception and Flood Insurance Purchase. Global Environmental Change, 23 (5), 1249-1257.

Lo, A. Y., Chow, A. T., \& Cheung, S. M. (2012). Significance of Perceived Social Expectation and Implications to Conservation Education: Turtle Conservation as a Case Study. Environmental Management, 50 (5), 900-913.

Miceli, R., Sotgiu, I., \& Settanni, M. (2008). Disaster preparedness and perception of flood risk: A study in an alpine valley in Italy. Journal of Environmental Psychology, 28 (2), 164-173.

National Bureau of Statistics of China. (2014). National Database. In. National Bureau of Statistics of China, Bejing

Norgaard, K. M. (2011). Living in Denial: Climate Change, Emotions, and Everyday Life. MIT Press Cambridge, Mass.

Owens, S. (2000). 'Engaging the public': Information and deliberation in environmental policy. Environment and Planning A, 32, 1141-1148.

Pelling, M. (2011). Adaptation to climate change : from resilience to transformation Routledge, Oxon, U.K.

Pelling, M., \& High, C. (2005). Understanding adaptation: What can social capital offer assessments of adaptive capacity? Global Environmental Change, 15, 308-319.

Pretty, J., \& Ward, H. (2001). Social Capital and the Environment. World Development, 29 (2), 209-227.

Putnam, R. D. (1995). Bowling Alone: America's Declining Social Capital. Journal of Democracy, 6 (1), 6578.

Rose, A. (2004). Defining and measuring economic resilience to disasters. Disaster Prevention and Management, 13 (4), 307-314.

Rose, A. (2007). Economic resilience to natural and man-made disasters: Multidisciplinary origins and contextual dimensions. Environmental Hazards, 7 (4), 383-398.

Suckall, N., Tompkins, E., \& Stringer, L. (2014). Identifying trade-offs between adaptation, mitigation and development in community responses to climate and socio-economic stresses: Evidence from Zanzibar, Tanzania. Applied Geography, 46 (0), 111-121.

Tianjin Bureau of Statistics. (2014). 2013 National Economic and Social Development in Tianjin. In. Tianjin Bureau of Statistics, Tianjin.

Vari, A., Linnerooth-Bayer, J., \& Ferencz, Z. (2003). Stakeholder Views on Flood Risk Management in Hungary's Upper Tisza Basin. Risk Analysis, 23 (3), 585-600.

Varis, O., Kummu, M., \& Salmivaara, A. (2012). Ten major rivers in monsoon Asia-Pacific: An assessment of vulnerability. Applied Geography, 32 (2), 441-454.

Wang, G., Liu, Y., Wang, H., \& Wang, X. (2014). A comprehensive risk analysis of coastal zones in China. Estuarine, Coastal and Shelf Science, $140(0), 22-31$.

Wang, M.-Z., Amati, M., \& Thomalla, F. (2012). Understanding the vulnerability of migrants in Shanghai to typhoons. Natural Hazards, 60 (3), 1189-1210.

Wilson, G. A. (2015). Community Resilience and Social Memory. Environmental Values, 24 (2), 227-257.

Wolf, J., Adger, W. N., Lorenzoni, I., Abrahamson, V., \& Raine, R. (2010). Social capital, individual responses to heat waves and climate change adaptation: An empirical study of two UK cities. Global Environmental Change, 20 (1), 44-52.

World Bank. (2010). Natural Hazards, UnNatural Disasters: The Economics of Effective Prevention. In. World Bank, Washington D.C. 
Wu, Q. Z. (2012). Discussion on rains and floods in Beijing and urban waterlogging prevention. China Ancient City, 10, 4-13 [in Chinese].

Xie, X. L., Lo, A. Y., Zheng, Y., Pan, J., \& Luo, J. (2014). Generic security concern influencing individual response to natural hazards: evidence from Shanghai, China. Area, 46 (2), 194-202.

Yu, H., Wang, B., Zhang, Y.-J., Wang, S., \& Wei, Y.-M. (2013). Public perception of climate change in China: results from the questionnaire survey. Natural Hazards, 69 (1), 459-472.

Zheng, Y., \& Dallimer, M. (2015). What motivates rural households to adapt to climate change? Climate and Development, 1-12. 
Table 1 Factor analysis of economic preparation variables

\begin{tabular}{|c|c|c|c|c|}
\hline & Mean & S.D. & Factor loading & $\begin{array}{c}\text { Cronbach's } \\
\text { alpha }\end{array}$ \\
\hline F1. Take out insurance & 3.37 & 1.23 & 0.534 & \\
\hline F2. Reduce expenses & 3.81 & 1.13 & 0.716 & \\
\hline F3. Arrange storage for valuables & 2.85 & 1.15 & 0.615 & 0.654 \\
\hline F4. Diversify sources of income & 3.16 & 1.24 & 0.709 & \\
\hline F5. Spread assets across different places & 3.10 & 1.26 & 0.655 & \\
\hline Eigenvalues & & & 2.106 & \\
\hline$\%$ of variance explained & & & 42.121 & \\
\hline
\end{tabular}

Higher mean values denote stronger intention to act

Factor extraction method: Principal Component Analysis with Varimax rotation. 
Table 2 Factor analysis of social capital variables

\begin{tabular}{|c|c|c|c|c|c|c|}
\hline & \multirow[t]{2}{*}{ Mean } & \multirow[t]{2}{*}{ S.D. } & \multicolumn{3}{|c|}{ Factor loading } & \multirow{2}{*}{$\begin{array}{l}\text { Cronbac } \\
\text { h's alpha }\end{array}$} \\
\hline & & & $\begin{array}{c}\text { Social } \\
\text { expectation }\end{array}$ & $\begin{array}{c}\text { Social } \\
\text { relationship }\end{array}$ & $\begin{array}{l}\text { Institution } \\
\text { al Trust }\end{array}$ & \\
\hline A1. Family expectation & 3.64 & 0.99 & .780 & & & \multirow{3}{*}{0.693} \\
\hline A2. Friends expectation & 3.65 & 0.88 & .837 & & & \\
\hline A3. Community expectation & 3.29 & 0.95 & .669 & & & \\
\hline B1. Relationship with family & 4.49 & 0.66 & & .835 & & \multirow{3}{*}{0.619} \\
\hline B2. Relationship with friends & 4.21 & 0.70 & & .832 & & \\
\hline B3. Relationship with community members & 3.64 & 0.74 & & .535 & & \\
\hline C1. Trust in municipal government & 3.47 & 1.03 & & & .836 & \multirow{2}{*}{0.676} \\
\hline C2. Trust in local residential committee & 2.95 & 1.07 & & & .836 & \\
\hline Eigenvalues & & & 1.857 & 1.749 & 1.574 & \\
\hline$\%$ of variance explained & & & 23.209 & 21.858 & 19.675 & \\
\hline
\end{tabular}

Higher mean values denote greater expectation (A1-A3), better relationship (B1-B2) and more trust (C1-C2)

Factor extraction method: Principal Component Analysis with Varimax rotation. 
Table 3 Descriptive statistics of model variables

\begin{tabular}{|c|c|c|c|c|}
\hline Variable & Description & Range & Mean & S.D. \\
\hline \multicolumn{5}{|c|}{ Socio-economic characteristics } \\
\hline Age & Open-ended & $16-90$ & 40.58 & 16.78 \\
\hline University degree & $1=$ University degree or higher, $0=$ otherwise & $0-1$ & 0.42 & 0.49 \\
\hline Female & $1=$ Female, $0=$ Male & $0-1$ & 0.49 & 0.50 \\
\hline $\begin{array}{l}\text { Monthly household } \\
\text { income }\end{array}$ & $\begin{array}{l}1=\$ 2,500 \text { or lower, } 2=\$ 2,500-\$ 3,500 \ldots . .6= \\
\$ 9,000 \text { or higher (in Chinese yuan) }\end{array}$ & $1-6$ & 5.28 & 1.53 \\
\hline $\begin{array}{l}\text { Ground-floor } \\
\text { resident }\end{array}$ & $\begin{array}{l}1=\text { Current home located at the ground floor of a } \\
\text { residential building, } 0=\text { Otherwise }\end{array}$ & $0-1$ & 0.13 & 0.34 \\
\hline \multicolumn{5}{|c|}{ Hazard experience and perception } \\
\hline Damage experience & $\begin{array}{l}1=\text { had suffered economic damage due to rainstorms } \\
\text { or floods, } 0=\text { Otherwise }\end{array}$ & $0-1$ & 0.16 & 0.36 \\
\hline $\begin{array}{l}\text { Level of damage } \\
\text { (actual) }\end{array}$ & $\begin{array}{l}1=\text { No damage, } 2 \text { = Minor damage ...... } 5 \text { = Extremely } \\
\text { damaging }\end{array}$ & $1-5$ & 1.44 & 0.81 \\
\hline $\begin{array}{l}\text { Level of damage } \\
\text { (expected) }\end{array}$ & $\begin{array}{l}1=\text { No damage, } 2 \text { = Minor damage ...... } 5 \text { = Extremely } \\
\text { damaging }\end{array}$ & $1-5$ & 2.30 & 0.98 \\
\hline $\begin{array}{l}\text { Perceived likelihood } \\
\text { (recurrence) }\end{array}$ & $\begin{array}{l}1=\text { Very unlikely, } 2 \text { = Not quite possible ...... } 5 \text { = Very } \\
\text { likely }\end{array}$ & $1-5$ & 2.85 & 0.99 \\
\hline $\begin{array}{l}\text { Perceived likelihood } \\
\text { (intensification) }\end{array}$ & $\begin{array}{l}1=\text { Very unlikely, } 2 \text { = Not quite possible ....... } 5 \text { = Very } \\
\text { likely }\end{array}$ & $1-5$ & 2.76 & 0.86 \\
\hline \multicolumn{5}{|l|}{ Social capital } \\
\hline Social expectation & $\begin{array}{l}\text { Composite scale }(\mathrm{A} 1-\mathrm{A} 3) \text {. Higher values denote } \\
\text { greater expectations }\end{array}$ & $3-15$ & 10.58 & 2.21 \\
\hline Social relationship & $\begin{array}{l}\text { Composite scale }(\mathrm{B} 1-\mathrm{B} 3) \text {. Higher values denote } \\
\text { better relationships }\end{array}$ & $3-15$ & 12.34 & 1.58 \\
\hline Institutional Trust & $\begin{array}{l}\text { Composite scale }(\mathrm{C} 1-\mathrm{C} 2) \text {. Higher values denote } \\
\text { higher level of trust }\end{array}$ & $2-10$ & 6.42 & 1.83 \\
\hline \multicolumn{5}{|l|}{ Dependent variable } \\
\hline $\begin{array}{l}\text { Intended economic } \\
\text { preparation }\end{array}$ & $\begin{array}{l}\text { Composite scale (F1 - F5). Higher values denote } \\
\text { greater intention to prepare for hazards }\end{array}$ & $5-24$ & 16.34 & 3.87 \\
\hline
\end{tabular}


Table 4 OLS Regression Analysis

\begin{tabular}{lccrr} 
& Coefficient & $\begin{array}{c}\text { Standard } \\
\text { Error }\end{array}$ & \multicolumn{2}{c}{$\begin{array}{c}\text { 95\% Confidence } \\
\text { Interval }\end{array}$} \\
\hline Age & $-0.088^{* *}$ & 0.012 & -0.113 & -0.064 \\
University degree & 0.076 & 0.417 & -0.745 & 0.897 \\
Female & -0.572 & 0.356 & -1.273 & 0.130 \\
Monthly household income & $0.446 * *$ & 0.125 & 0.200 & 0.693 \\
Ground-floor resident & -1.016 & 0.536 & -2.071 & 0.039 \\
Damage experience & -0.172 & 0.671 & -1.492 & 1.149 \\
Level of damage (actual) & 0.226 & 0.319 & -0.401 & 0.853 \\
Level of damage (expected) & 0.330 & 0.198 & -0.059 & 0.720 \\
Perceived likelihood (recurrence) & 0.405 & 0.219 & -0.025 & 0.836 \\
Perceived likelihood (intensification) & 0.334 & 0.239 & -0.136 & 0.803 \\
Social expectation & $0.214 *$ & 0.100 & 0.016 & 0.412 \\
Social relationship & $0.274 *$ & 0.123 & 0.031 & 0.516 \\
Institutional Trust & $0.239 *$ & 0.106 & 0.030 & 0.448 \\
(Constant) & 8.490 & 1.843 & 4.862 & 12.119 \\
\hline Adj. $\mathrm{R}^{2}$ & 0.394 & & & \\
F (13, 274) & 15.330 & & & \\
Prob > F & 0.000 & & & \\
Number of observations & 288 & & & \\
\hline Dependent variable: Intended & & & & \\
\hline
\end{tabular}

Dependent variable: Intended economic preparation

** and * denote significance at .01 and .05 levels respectively. 


\section{Appendix}

Table A1 Distribution of respondents by intended economic preparation

Intended economic preparation

Percentage of respondents (\%)

Definitely not (1) / Not sure Probably (4) /

probably not (2) (3) definitely (5)

F1. If you could, how likely would you take out

15.5

13.1

71.4

insurance to cover your potential losses arising from

urban flood hazards?

F2. If catastrophic rainstorms or flooding increase

28.6

12.8

58.6

your daily expenses, how likely would you try to

reduce your expenses without compromising standard

of living?

F3. If you could, how likely would you arrange

46.5

19.8

33.7

temporary storage in advance for your valuables

when a major catastrophe event occurs?

F4. How likely would you seek out multiple sources

of income?

F5. If you could, how likely would you acquire

13.4

52.9

properties or motor vehicles in other Districts in

36.1

15.5

48.5 order to spread the financial risks of natural hazards?

Measured on a five-point Likert scale 
Table A2 Distribution of respondents by level of damage due to catastrophic rainstorms or flooding

Level of damage

Percentage of respondents (\%)

$\begin{array}{ccc}\text { No damage (1) / } & \text { Some } & \text { Fairly damaging } \\ \text { minor damage (2) } & \text { damage } & \text { (4)/ extremely }\end{array}$

minor damage (2) damage (4) / extremely

(3) damaging (5)

\begin{tabular}{lccc}
\hline $\begin{array}{l}\text { Actual: How damaging were the last major } \\
\text { catastrophic rainstorms or flooding to you and } \\
\text { your family? }\end{array}$ & 85.6 & 12.5 & 1.9 \\
$\begin{array}{l}\text { Expected: How much personal damage would } \\
\text { a major catastrophic event like the } 2012\end{array}$ & 61.6 & 27.4 & 10.9 \\
rainstorms cause?
\end{tabular}

Measured on a five-point Likert scale 
Table A3 Distribution of respondents by perceived likelihood of catastrophic rainstorms or flooding

Perceived likelihood of urban flood hazards

Percentage of respondents (\%)

Very likely (1) / not Maybe Possible (4) /

quite possible (2) (3) $\quad$ very likely (5)

Recurrence: How likely is Tianjin to experience a

35.6

42.9

21.6

major catastrophic event like the 2012 rainstorms

in the next 10 years?

Intensification: Do you think these rainstorms or

40.1

44.0

15.9

flooding would become more frequent and

severe in the next 20 years?

Measured on a five-point Likert scale 
Table A4 Distribution of respondents by social expectation

Social expectation

Percentage of respondents (\%)

Definitely not (1) Not sure (3) Probably (4) /

/ probably not (2)

A1. Do you think your family would encourage

15.5 definitely (5)

you to prepare for urban flood hazards?

A2. Do you think your friends would encourage

12.2

21.6

65.6

you to prepare for urban flood hazards?

A3. Do you think other people in your residential

22.0

29.1

66.2

community would encourage you to prepare for

urban flood hazards?

Measured on a five-point Likert scale 
Table A5 Distribution of respondents by social relationship

\begin{tabular}{lccccc} 
Social relationship & \multicolumn{5}{c}{ Percentage of respondents (\%) } \\
& Very bad (1) & Bad (2) & Fair (3) & Good (4) & Very good (5) \\
\hline $\begin{array}{l}\text { B1. How is your relationship with } \\
\text { your family? }\end{array}$ & 0.6 & 0.0 & 5.5 & 37.7 & 56.2 \\
$\begin{array}{l}\text { B2. How is your relationship with } \\
\text { your friends? }\end{array}$ & 0.3 & 0.6 & 12.2 & 51.4 & 35.6 \\
$\begin{array}{l}\text { B3. How is your relationship with } \\
\text { other people in your residential } \\
\text { community? }\end{array}$ & 1.2 & 0.6 & 42.9 & 43.5 & 11.9 \\
\hline $\begin{array}{l}\text { Measured on a five-point Likert scale } \\
\text { neared }\end{array}$ & & & & & \\
\hline
\end{tabular}


Table A6 Distribution of respondents by Institutional Trust

Institutional Trust

Percentage of respondents (\%)

Absolutely not Not sure (3) Likely (4) /

(1) / not likely (2) Absolutely (5)

C1. Do you trust that the municipal government

19.2

25.6

55.2

can help residents cope with the impacts of urban

flood hazards?

C2. Do you trust that your local residential

35.9

32.5

31.6 committee can help residents cope with the impacts of urban flood hazards?

Measured on a five-point Likert scale 


\section{Caption for figures}

Figure 1: Map of Tianjin

Figure 2: View from a medium-rise building over the Yuexiu Road Community in the Hexi District of Tianjin, a megacity in China. In the old core districts, buildings are closely packed and human activities are highly concentrated. Both residents and infrastructures are vulnerable to waterlogging and inundation in the event of flooding and/or rainstorm.

Figure 3: View from a typical alley in Dongshezhai Community in the Hexi District of Tianjin, which is located in close proximity to a major river called 'Haihe'. Residents in the old core districts often park their cars and bikes along curbside, with minimal protection from floods, due to limited space within the private residential area. Lower-floor residents are particularly vulnerable due to their location and the concentration of assets. 